\title{
Role of Nepafenac $0.1 \%$ Ophthalmic Solution in Preventing Intraoperative Miosis during Phacoemulsification
}

\author{
Sairam Ahmed ${ }^{1}$, lqra Ghazanfar², Fuad Ahmad Khan Niazi ${ }^{3}$, Ali Raza ${ }^{4}$ \\ ${ }^{1-4}$ Holy Family Hospital, Rawalpindi Medical University
}

\begin{abstract}
Purpose: To compare $0.1 \%$ Nepafenac ophthalmic solution with placebo in terms of decreasing mean intraoperative miosis in patients undergoing cataract surgery.
\end{abstract}

Study Design: Quasi experimental study.

Place and Duration of Study: Department of Ophthalmology, Holy-Family Hospital Rawalpindi from September 2017 to March 2018.

Methods: A total of 150 eyes with senile cataract of patients between $40-80$ years of age and of both genders, undergoing uneventful cataract surgery and fulfilling the inclusion criteria were included. Patients were divided into 2 equal groups. Group A received Nepafenac eye drops and group B received placebo drops (Preservative free artificial tears). The diameter of pupil as viewed through the operating microscope was measured with Castroviejo Caliper at following steps; immediately before the start of surgery (baseline), after complete nucleus removal and at the end of surgery.

Results: Mean decrease in pupil size from the start of surgery to the end of phacoemulsification in Group A (nepafenac group) was $0.48 \pm 0.26 \mathrm{~mm}$ while in Group B (placebo group) it was $1.40 \pm 0.49 \mathrm{~mm}(P=0.0001)$. Mean decrease in pupil size from start to end in Group A (Nepafenac group) was $0.75 \pm 0.32 \mathrm{~mm}$ while in Group $B$ (placebo group) was $2.02 \pm 0.62 \mathrm{~mm}(P=0.0001)$.

Conclusion: Intraoperative miosis in terms of mean decrease in pupils size (both from start of surgery till phacoemulsification and also from start of surgery till end of surgery) was lower in $0.1 \%$ Nepafenac group as compared to placebo group.

Key Words: Phacoemulsification, Miosis, Nepafenac.

How to Cite this Article: Ahmed S, Ghazanfar I, Niazi FAK, Raza A. Role of Nepafenac $0.1 \%$ Ophthalmic Solution in Preventing Intraoperative Miosis during Phacoemulsification. Pak J Ophthalmol. 2021, 37 (1): 92-96.

Doi: https://doi.org/10.36351/pjo.v37i1.1038

\section{INTRODUCTION}

Phacoemulsification with foldable intraocular lens implantation is the treatment of choice for cataract. ${ }^{1}$

Correspondence: Sairam Ahmed

Holy Family Hospital, Rawalpindi Medical University

Email: sairamahmed90@gmail.com

Received: April 14, 2020

Accepted: September 27, 2020
Preoperative dilation of pupil is the most important prerequisite for cataract surgery especially during phacoemulsification. Constriction of pupil during surgery can lead to increased difficulty in surgery and greater chances of complications.

Tropicamide $1 \%$ (anticholinergic agent) and phenylephrine $2.5 \%$ (sympathomimetic agent) are used before surgery for pupil dilation. Addition of adrenaline in the irrigation fluid used during surgery also has a role in dilatation of the pupil. As the lens is 
situated behind the iris, sufficient dilatation of the pupil is necessary for cataract extraction. ${ }^{2}$ In case of adequately dilated pupil visibility of the posterior chamber structures is improved, hence surgery can be accomplished more easily and safely. It has been described that with pupillary diameter of more than 6 $\mathrm{mm}$ the rate of complications during surgery especially posterior capsular rupture is reduced. ${ }^{2}$

Surgical trauma during cataract surgery results in breakdown of blood aqueous barrier. This results in release of prostaglandins in the anterior chamber, which has a role in constriction of the pupil. ${ }^{3}$ Preoperative administration of nonsteroidal antiinflammatory drugs (NSAIDs) results in decrease in synthesis of prostaglandins through inhibition of Cyclo-Oxygenase (COX) enzyme.

Nepafenac $0.1 \%$ is an ophthalmic NSAID with an inert and prodrug structure. ${ }^{4}$ Nepafenac has a neutral molecule in contrast to acidic nature of the other topical NSAIDs. This allows Nepafenac to enter through the corneal surface into the anterior chamber. Intraocular hydrolases convert it to more active compound Amfenac. ${ }^{4}$ These hydrolase enzymes are usually present in iris, ciliary body, retina and choroid. ${ }^{4}$ So, Nepafenac is unique to other NSAIDs in that its transformation to active product Amfenac occurs in the target tissues where its action is required.

Previous studies have confirmed effectiveness of various topical NSAIDs in preventing intraoperative miosis during cataract surgery. Commonly used NSAIDs eye drops include Diclofenac, Flurbiprofen, Indomethacin and Ketrolac, which have shown efficacy in reducing intraoperative miosis during cataract surgery. ${ }^{4}$ The lower side effects and better bioavailability profile of Nepafenac makes its use superior as compared to other NSAIDs used traditionally in preoperative period of cataract surgery.

Our study determined the role of Nepafenac in reducing intraoperative miosis during cataract surgery. Currently there are no specific guidelines for use of Nepafenac in the preoperative period for preventing pupillary constriction during cataract surgery. If effective, this will ultimately lead to decrease in intraoperative complications related to intra-operative miosis of the pupil.

\section{METHODS}

We conducted this study in the Department of Ophthalmology, Holy Family Hospital Rawalpindi
Medical University. A sample size of 150 eyes was calculated with WHO sample size calculator. Sampling was done from $1^{\text {st }}$ September, 2017 to $1^{\text {st }}$ March, 2018. Consecutive sampling technique was adopted. Both male and female patients with age between 40 to 70 years and diagnosed with senile cataract were included in the study. All patients included in the study underwent uneventful cataract surgery. All patients with any local pupillary abnormality, pseudoexfoliation, history of ocular trauma, complicated cataract, intraoperative complications, glaucoma, previous intraocular surgery to the same eye, diabetes mellitus, hypertension, pupil size less than $6 \mathrm{~mm}$ before the surgery and hypersensitivity to NSAIDs were excluded from the study. After approval from the ethical committee and taking informed verbal consent, all the patients fulfilling the selection criteria were included in the study. Patients were divided into 2 equal groups. Using SPSS, a randomly generated list of 150 cases were randomly allocated to either group A or Group B, each with 75 patients. Each patient fulfilling the selection criteria and consenting for study was assigned chronological ID number and was assigned respective study group $\mathrm{A}$ or $\mathrm{B}$ according to the allocation in the list. The sequence of allocation in the list was followed until the sample size of 150 was attained. Group A patients received Nepafenac eye drops ( 3 drops; 1 drop at 15 minutes interval beginning 1 hour before surgery) and group B received placebo drops (Preservative-free tears solution). Additionally, the pupil was dilated with topical tropicamide $1 \%$ (3 drops; 1 drop every 15 minutes beginning 1 hour before surgery) in both groups. No other drug was used pre-operatively or intra-operatively. All surgeries were done by the same surgeon. The surgeon was masked to patient randomization. All eyes had phacoemulsification and posterior chamber foldable intraocular lens (PC IOL) implantation. The diameter of pupil as viewed through the operating microscope was measured with Castroviejo Caliper at following steps; immediately before the start of surgery (baseline), at the end of phacoemulsification and at the end of surgery. Data entry and analysis was done by using SPSS 20. The mean diameter of pupil was measured at 3 surgical steps i.e. before start of surgery, at the end of nucleus removal and at the end of the surgery. Mean decrease in pupil size from start of the surgery to end of nucleus removal and from start of the surgery to the end of surgery was calculated in both groups. The significance of difference in the mean 
Table 1: Mean Pupil Size in both groups.

\begin{tabular}{|c|c|c|c|c|c|}
\hline & Group & $\mathbf{N}$ & Mean & SD & P-value \\
\hline \multirow{2}{*}{ Pre-Operative Pupil Size } & Nepafenac & 75 & 8.03 & 0.72 & \multirow{2}{*}{0.004} \\
\hline & Placebo & 75 & 7.72 & 0.54 & \\
\hline \multirow{2}{*}{ Pupil Size after complete removal of nucleus in both groups. } & Nepafenac & 75 & 7.56 & 0.79 & \multirow{2}{*}{0.0001} \\
\hline & Placebo & 75 & 6.32 & 0.88 & \\
\hline \multirow{2}{*}{ Pupil Size at the end of surgery } & Nepafenac & 75 & 7.26 & 0.78 & \multirow{2}{*}{0.0001} \\
\hline & Placebo & 75 & 5.71 & 0.98 & \\
\hline \multirow{2}{*}{ Decrease in pupil size from start of surgery to end of phacoemulsification } & Nepafenac & 75 & 0.48 & 0.26 & \multirow{2}{*}{0.0001} \\
\hline & Placebo & 75 & 1.40 & 0.49 & \\
\hline \multirow{2}{*}{ Decrease in pupil size from start to end } & Nepafenac & 75 & 0.75 & 0.32 & \multirow{2}{*}{0.0001} \\
\hline & Placebo & 75 & 2.02 & 0.62 & \\
\hline
\end{tabular}

decrease in pupil size between the two groups was determined using the student $\mathrm{t}$ test.

\section{RESULTS}

Age range in this study was from 40 to 80 years with mean age of $59.55 \pm 0.585$ years. Out of 150 patients $81(54.0 \%)$ were males and $69(46.0 \%)$ were females with male to female ratio of 1.2:1. Mean pre-operative pupil size in Group A (Nepafenac group) was $8.03 \pm$ $0.72 \mathrm{~mm}$ while in Group B (placebo group) was $7.72 \pm$ $0.54 \mathrm{~mm}$ as shown in Table $1(\mathrm{P}$-value $=0.004)$. Further details are shown in table 1.

\section{DISCUSSION}

With substantial advancement in surgical techniques and equipment for phacoemulsification, current cataract surgery has attained a drop of physical surgical insult and a reduction in the release of inflammatory mediators especially prostaglandins, which play a key role in the development of postoperative ocular inflammation..$^{5-6}$ Nevertheless, most patients still manifest clinically significant ocular inflammation after surgery. This uncontrolled intraocular inflammation leads to disruption of bloodocular barrier and results in entrance of inflammatory mediators like prostaglandins and cytokines into aqueous humor. These inflammatory mediators are a major source of patient distress, late recovery, hyperemia, photophobia and suboptimal visual outcomes. If allowed to continue, uncontrolled release of these mediators can result in serious complications like cystoid macular edema (CME), synechiae formation, corneal edema and raised intraocular pressure (IOP). ${ }^{6-8}$ In this era of patients' high expectations and with introduction of latest apparatus and finest quality of intraocular lenses, postoperative discomfort and delayed recovery are un-desirable to patients.

Surgical trauma triggers the inflammatory cascade in the eye, thereby releasing different types of inflammatory mediators such as prostaglandins (PG), prostacyclin, thromboxane A2, leukotrienes, lipoxins, hepoxylins, and platelet-activating factor. These substances are involved in intraoperative and postoperative pain, conjunctival congestion and hyperemia, intra-operative pupillary constriction, increase in intraocular pressure (IOP), synechiae formation, posterior capsular opacification, and surgically induced cystoid macular edema (CME). ${ }^{9}$ By inhibiting the release of these inflammatory mediators with pre-operative use of topical nonsteroidal antiinflammatory drugs (NSAIDs), mydriasis is adequately maintained during surgery. This may ultimately result in decrease in intra-operative and post-operative complications related to prostaglandins. ${ }^{10}$ Nepafenac has also shown similar favourable effects. It has a prodrug structure, which is hydrolyzed by intraocular enzymes to Amfenac which is a potent inhibitor of cyclooxygenase- $1(\mathrm{COX}-1)$ and COX-2 enzymes. ${ }^{11}$ High ocular bioavailability, permeability and quick activation by intra-ocular hydrolases by the ocular tissues, make Nepafenac a unique and target-specific drug for the inhibition of prostaglandin formation in the anterior and posterior segments of the eye where, its action is required. ${ }^{12}$ Its availability in a prodrug structure also helps in reduction of toxicity on the corneal surface and improves its infiltration into specific tissues. ${ }^{13-14}$

Previous studies have confirmed effectiveness of various topical NSAIDs in preventing intraoperative miosis during cataract surgery. Study conducted in Egypt by Abdel et al reported that use of topical flurbiprofen $0.03 \%$ and dexamethasone acetate $0.1 \%$ was effective in maintaining intra-operative pupillary dilatation. ${ }^{15}$ In that study flurbiprofen had superior and 
prolonged effect as compared to dexamethasone. Similar results were shown by Gimbel et al in which flurbiprofen $0.03 \%$ and indomethacin $1 \%$ had similar effect in preventing pupillary constriction during cataract surgery. ${ }^{16}$ Moreover, Zanetti et al showed superior effect of prednisolone acetate, ketorolac tromethamine and Nepafenac in maintaining intraoperative mydriasis as compared to placebo. ${ }^{17}$

In 2009, Cervantes-Coste et al. showed that Nepafenac was effective in preventing pupillary constriction as compared to placebo during cataract surgery. There was a statistically significant difference in pupillary diameter from the start of surgery to the end of surgery between Nepafenac group $(6.84 \pm 0.93$ $\mathrm{mm})$ and the placebo group $(7.91 \pm 0.74 \mathrm{~mm}) .{ }^{18}$

In a prospective, randomized, double-masked comparative study, which included adult cataract patients, the researchers used topical NSAIDs (Ketorolac or Nepafenac) or balanced salt solution (control) prior to phacoemulsification and capsular bag intraocular-lens (IOL) implantation. ${ }^{19}$ A total of 47 eyes of 44 cataract surgery patients, 13 males and 34 females, with a mean age of $66.04 \pm 8.87$ years, were included in the study. The mean horizontal and vertical diameters of pupils in the three groups were similar at the start of surgery. Significant differences were seen after IOL implantation, with the Nepafenac group having the largest mean diameters in both horizontal $(\mathrm{p}=0.012)$ and vertical $(\mathrm{p}=0.012)$ pupil measurements. ${ }^{19}$ Other studies have also reported similar results. $^{20,21}$

A study conducted in India by Sarkar et $\mathrm{al}^{2}$ reported that the decrease in horizontal pupillary diameter from the start of surgery to end of surgery was significantly $(P=0.009)$ less in Nepafenac group compared to Flurbiprofen group. Study done in Hyderabad by Surhio et $\mathrm{al}^{3}$ in 2013 reported that the mean reduction in pupillary size from the start of surgery to the end of phacoemulsification was $0.20 \pm$ $0.31 \mathrm{~mm}$ in Nepafenac group as compared to $0.73 \pm$ $0.60 \mathrm{~mm}$ in placebo group ( $\mathrm{P}-$ Value $<0.001)$. Mean reduction in pupillary size from the start of surgery to the end of surgery was $0.55 \pm 0.51 \mathrm{~mm}$ in Nepafenac group as compared to $1.05 \pm 0.87 \mathrm{~mm}$ in placebo group $(\mathrm{P}=0.009)$.

\section{CONCLUSION}

Intraoperative miosis in terms of mean decrease in pupil size (both from start of surgery to phacoemulsification and also from start of surgery to the end of surgery) is lower in $0.1 \%$ Nepafenac group as compared to placebo.

\section{Ethical Approval}

The study was approved by the Institutional review board/Ethical review board. (R-17/RMU)

\section{Conflict of Interest}

Authors declared no conflict of interest.

\section{REFERENCES}

1. Carifi G, Miller MH, Pitsas C, Zygoura V, Deshmukh RR, Kopsachilis N, et al. Complications and outcomes of phacoemulsification cataract surgery complicated by anterior capsule tear. Am J Ophthalmol. 2015; 159 (3): 463-469.

2. Sarkar S, Mondal KK, Roy SS, Gayen S, Ghosh A, De RR. Comparison of preoperative nepafenac $(0.1 \%)$ and flurbiprofen $(0.03 \%)$ eye drops in maintaining mydriasis during small incision cataract surgery in patients with senile cataract: A randomized, doubleblind study. Indian J Pharmacol. 2015; 47 (5): 491.

3. Surhio SA, Memon M, Talpur R, Talpur KI. Efficacy of Nepafenac $0.1 \%$ in Maintaining Mydriasis during Phacoemulsification Surgery. J Liaquat Uni Med Health Sci. 2013; 12 (02): 74.

4. Wilson DJ, Schutte SM, Abel SR. Comparing the efficacy of ophthalmic NSAIDs in common indications: a literature review to support cost-effective prescribing. Ann Pharmacother. 2015; 49 (6): 727-734.

5. Simone JN, Pendelton RA, Jenkins JE. Comparison of the efficacy and safety of ketorolac tromethamine $0.5 \%$ and prednisolone acetate $1 \%$ after cataract surgery. J Cataract Refract Surg. 1999; 25 (5): 699704 .

6. Jones BM, Neville MW. Nepafenac: an ophthalmic nonsteroidal antiinflammatory drug for pain after cataract surgery. Ann Pharmacother. 2013; 47 (6): 892896.

7. Sahu S, Ram J, Bansal R, Pandav SS, Gupta A. Effect of topical ketorolac $0.4 \%$, nepafenac $0.1 \%$, and bromfenac $0.09 \%$ on postoperative inflammation using laser flare photometry in patients having phacoemulsification. J Cataract Refract Surg. 2015; 41 (10): 2043-2048.

8. Duffin RM, Camras CB, Gardner SK, Pettit TH. Inhibitors of surgically induced miosis. Ophthalmology, 1982; 89 (8): 966-979.

9. Podos SM. Prostaglandins, nonsteroidal antiinflammatory agents and eye disease. Trans Am Ophthalmol Soc. 1976; 74: 637-660. 
10. Muhtaseb M, Kalhoro A, Ionides A. A system for preoperative stratification of cataract patients according to risk of intraoperative complications: A prospective analysis of 1441 cases. Br J Ophthalmol. 2004; 88: 1242-1246.

11. Lane SS. Nepafenac: A unique nonsteroidal prodrug. Int Ophthalmol Clin. 2006; 46: 13-20.

12. Raizman M, Ernest P, Gayton J, Lehmann R. In vivo pharmacokinetics and in vitro pharmacodynamics of nepafenac, amfenac, ketorolac, and bromfenac. J Cataract Refract Surg. 2007; 33: 1539-1545.

13. Ke TL, Graff G, Spellman JM, Yanni JM. Nepafenac, a unique nonsteroidal prodrug with potential utility in the treatment of trauma-induced ocular inflammation: II. In vitro bioactivation and permeation of external ocular barriers. Inflammation, 2000; 24: 371-384.

14. Lindstrom R, Kim T. Ocular permeation and inhibition of retinal inflammation: An examination of data and expert opinion on the clinical utility of nepafenac. Curr Med Res Opin. 2006; 22: 397-404.

15. Abdel M, Mahdy S. Effect of flurbiprofen and dexamethasone acetate in prevention of surgically induced miosis during cataract surgery. J Am Sci. 2011; 7: 474-478.

16. Gimbel H, Van Westenbrugge J, Cheetham JK, DeGryse R, Garcia CG. Intraocular availability and pupillary effect of flurbiprofen and indomethacin during cataract surgery. J Cataract Refract Surg. 1996; 22: 474-479.

17. Zanetti FR, Fulco EA, Chaves FR, da Costa Pinto AP, Arieta CE, Lira RP. Effect of preoperative use of topical prednisolone acetate, ketorolac tromethamine, nepafenac and placebo, on the maintenance of intraoperative mydriasis during cataract surgery: a randomized trial. Indian J Ophthalmol. 2012; 60 (4): 277.
18. Cervantes-Coste G, Sánchez-Castro YG, OrozcoCarroll M, Mendoza-Schuster E, Velasco-Barona C. Inhibition of surgically induced miosis and prevention of postoperative macular edema with nepafenac. Clin Ophthalmol. 2009; 3: 219-226.

19. Atanis R, Tuaño PM, Vicencio J, Martinez JM, Verzosa L. Effect of topical ketorolac tromethamine and topical nepafenac on maintaining pupillary dilation during phacoemulsification. Philipp J Ophthalmol. 2011; 36: 23-27.

20. Mahdy MA. Effect of flurbiprofen and dexamethasone acetate in prevention of surgically induced miosis during cataract surgery. J Am Sci. 2011; 7: 474-478.

21. Gamache DA, Graff G, Brady MT, Spellman JM, Yanni JM. Nepafenac, a unique nonsteroidal prodrug with potential utility in the treatment of trauma-induced ocular inflammation: I. Assessment of antiinflammatory efficacy. Inflammation, 2000; 24: 357370 .

\section{Authors' Designation and Contribution}

Sairam Ahmed; Post Graduate Trainee: Concepts, Literature research, Data Analysis, Statistical analysis, Manuscript preparation, Manuscript review.

Iqra Ghazanfar; Medical Officer: Design, Literature research, Data acquisition, Manuscript preparation.

Fuad Ahmad Khan Niazi; Professor: Data acquisition, Manuscript editing, Manuscript review.

Ali Raza; Professor: Data Analysis, Statistical analysis, Manuscript editing, Manuscript review. 